ORIGINAL RESEARCH ARTICLE

\title{
Assessment of Emergency Obstetric Care Services in Ibadan- Ibarapa Health Zone, Oyo State, Nigeria
}

\author{
Eniola A. Bamgboye ${ }^{1 *}$, Akindele O. Adebiyi ${ }^{2}$ and Akin A. Fatiregun ${ }^{1}$
}

Department of Epidemiology and Medical Statistics, College of Medicine, Faculty of Public Health, University of Ibadan, Ibadan $^{1}$, Department of Community Medicine, College of Medicine, Faculty of Public Health, University of Ibadan, Ibadan ${ }^{2}$.

*For Correspondence: E-mail: dr_enip@yahoo.co.uk; Phone: +2348029537711

\begin{abstract}
Nigeria's high maternal mortality has been attributed to poor utilization of obstetric care services to handle complications of pregnancy and childbirth. But how available are standard emergency obstetric care services? This facility based cross sectional study assessed the availability and accessibility of emergency obstetric care services in Oyo State, Nigeria. Using a multi-stage sampling technique, 61 primary and 10 secondary health care facilities were selected. Data was collected using a structured questionnaire from the heads of the maternity units. Spatial mapping of the facilities was also produced. Results showed availability of comprehensive emergency obstetric care (CEmOC) facilities (0-3.9/500,000 population) was adequate, however a gross lack of basic emergency obstetric care (BEmOC) facilities (0-5.4/500,000 population) was observed, where available, they were clustered in the urban settlements. Prompt action needs to be taken to upgrade basic emergency obstetric care facilities accessible to the larger rural population dwellers to improve maternal health indices. (Afr J Reprod Health 2016; 20[1]: 88-97).
\end{abstract}

Keywords: Maternal Mortality, Comprehensive, Basic, Emergency obstetric care

\section{Résumé}

la mortalité maternelle élevée du Nigeria a été attribuée à une mauvaise utilisation des services de soins obstétricaux pour traiter les complications de la grossesse et de l'accouchement. Mais comment disponibles sont les services de soins obstétricaux d'urgence norme? Cette facilité d'étude en coupe transversale basée a évalué la disponibilité et l'accessibilité des services de soins obstétricaux d'urgence dans l'Etat d'Oyo, Nigeria. En utilisant une technique d'échantillonnage à plusieurs degrés, 61 primaires et 10 secondaires des établissements de soins de santé ont été sélectionnés. Les données ont été recueillies à l'aide d'un questionnaire structuré à partir des chefs des unités de maternité. la cartographie spatiale des installations a également été produit. Les résultats ont montré la disponibilité des soins obstétricaux d'urgence complets (SOU) installations (0 à 3,9/500 000 habitants) était suffisante, mais un manque flagrant de soins obstétricaux d'urgence de base (BEmONC) installations $(0$ à 5,4/500 000 habitants) a été observée, le cas échéant, ils ont été regroupés dans les agglomérations urbaines. Une action rapide doit être prise pour mettre à niveau des établissements de soins obstétricaux d'urgence de base accessibles aux plus grandes populations rura les les habitants pour améliorer les indices de santé maternelle. (Afr J Reprod Health 2016; 20[1]: 88-97).

Mots-clés: Mortalité globale, de base, soins obstétricaux d'urgence maternels

\section{Introduction}

Poor obstetric outcome in middle and low-income countries like Nigeria with the attendant problems of maternal mortality remains a depressing and challenging health concern worldwide. According to the latest UN estimates, 287,000 women still die each year from complications of pregnancy and childbirth, and millions remain disabled. Unfortunately, $99 \%$ of these deaths take place in developing countries, most of them in sub-Saharan Africa. Implicated in this ugly trend is inadequate obstetric care service, especially at the primary health care level ${ }^{1-3}$.

The UN concern of the high maternal mortality in developing countries prompted the inclusion of MDG 5 in the Millennium Declaration with a target to reduce the Maternal Mortality Ratio (MMR) by 2015 to three-quarters of its value in 1990. An important indicator for measuring progress towards this target is the proportion of births with skilled attendants ${ }^{1-3}$. Unfortunately, Nigeria with a maternal mortality ratio of 545 per 100,000 live births has one of the highest mortality ratios in sub 
Saharan Africa and worldwide it is second only to India $^{2}$. Thus Nigeria, with only $2 \%$ of the worlds' population accounts for over $10 \%$ of the world's maternal deaths ${ }^{2}$.

Studies have shown that maternal mortality can be prevented by intervening at 3 levels of prevention: primary, secondary and tertiary. Primary prevention involves the reduction in untimed and unwanted pregnancies that place women at risk of death. Secondary prevention emphasizes Focused Antenatal Care (FAC) which detects potential problems that may lead to pregnancy complications and resolves them before they become late. And Tertiary prevention is the prompt treatment of complications that may lead to maternal death and this includes the provision of Emergency Obstetric Care Services ${ }^{4}$.

In developing countries, studies also showed that at least $15 \%$ of all pregnancies are expected to require an emergency medical intervention and the outcome of majority of severe complications cannot be predicted, but many can be treated if emergency obstetric care is available, accessible and of good quality ${ }^{5,6}$. Evidence also showed that access to appropriate health care including skilled birth attendance at delivery and timely referrals to emergency obstetric care services can greatly reduce maternal deaths and disabilities ${ }^{7}$. Almost $100 \%$ of births in developed countries occur with skilled birth attendants, but more than a half of all births in subSaharan Africa still take place without the assistance of skilled birth attendants ${ }^{6,7}$. In Nigeria, only about $38 \%$ of all births take place in a health facility out of which $39 \%$ of them are attended to by skilled health workers (doctors, nurses/midwives, auxiliary nurse/midwife). These low proportions have been ascribed to non-availability and accessibility of maternal services, inadequate health workers, perceived poor quality of health care delivery and lack of knowledge of where to receive adequate obstetric care ${ }^{8}$.

Thus the importance of Emergency Obstetric Care (EmOC) which describes the elements of obstetric care for management of complications arising during pregnancy, delivery and the postpartum period cannot be over-emphasized. It specifically ensures timely access to care of women experiencing complications. It has two components - Basic and Comprehensive EmOC, based on the performance of various services referred to as signal functions ${ }^{9}$. Basic EmOC (BEmOC) service comprises the performance of the following signal functions: administration of potent parenteral antibiotics for treatment of sepsis, parenteral oxytocic drugs and parental anticonvulsants for treatment of eclampsia, manual removal of placenta, removal of retained products of conception and assisted vaginal delivery using forceps or vacuum extractor. While Comprehensive EmOC (CEmOC) services include, Caesarean section with anaesthesia and safe blood transfusion in addition to all Basic EmOC services?.

In pursuance of improving the availability, accessibility, quality and use of Emergency Obstetric Care (EmOC) Services, the World Health Organization (WHO), UNICEF and the UN Population Fund (UNFPA) developed process indicators with minimum acceptable levels as follows: provision of at least four $\mathrm{BEmOC}$ and one $\mathrm{CEmOC}$ facilities for every 500,000 population; $100 \%$ of district areas to have the minimum acceptable numbers of BEmOC and CEmOC facilities in selected areas; at least $15 \%$ of all births in the population must take place in EmOC facilities; $100 \%$ of women estimated to have obstetric complications must be treated in EmOC facilities; estimated proportion of births by caesarean section in the population should not be less than $5 \%$ or more than $15 \%$ and the case fatality rate among women with obstetric complications in EmOC facilities should be less than $1 \% 9$.

A cross-sectional survey to assess the status of EmOC services in 378 health facilities in six developing countries in West Africa, Nigeria inclusive showed that only $2.3 \%$ of the designated facilities could provide BEmOC services while $23.1 \%$ of the CEmOC designated facilities were functional. Although, the total number of facilities for the population was adequate, none of the facilities met the minimum UN coverage rates for EmOC. This shows that health facilities in developing countries do not currently have the capacity to adequately respond to and manage women's obstetric complications ${ }^{10}$.

A national study to determine the availability, pattern of utilization and quality of essential obstetric care (EOC) facilities in Nigeria reported that only about a fifth of all the health care facilities met the criteria for EmOC with $4.2 \%$ for public facilities $(1.2 \%$ for BEmOC and $3.9 \%$ for CEmOC) and $32.8 \%$ for private facilities $(5.3 \%$ for BEmOC and $27.5 \%$ for CEmOC). However, the proportion of deliveries that took place in facilities meeting EOC criteria was just $5.9 \%$, which 
indicates an unmet need for EOC as $15 \%$ of pregnant women would be expected to have complications and should require EOC services ${ }^{11}$. In spite of the high attendance of antenatal services in Oyo State, South Western Nigeria, a summary of maternal mortality ratio showed figures that ranged from 143 to 543 deaths per 100,000 live births between January and December 2011. This high maternal mortality can be attributed to poor maternal services ${ }^{13}$.

Albeit, there is paucity of such good-quality data evaluating these obstetric care services especially basic and comprehensive emergency services in Nigeria as a country and also at the state level. This study therefore has examined the availability, accessibility and pattern of utilization of Emergency Obstetric Care services in Oyo State. This finding would contribute to the dearth of data necessary for the monitoring and evaluation of the progress in the provision of EmOC services. In addition it would inform policy and programme actions both at the level of the health facility and at the State level in Oyo State.

\section{Methods}

The study was carried out between April 2014 and December 2014 in Oyo State, South West Nigeria. Oyo State has an estimated population of about $5,580,894$ and made up of 33 local governments divided into three senatorial zones: Oyo South (9 LGAs), Oyo North (13 LGAs) and Oyo Central (11 LGAs) ${ }^{13}$

Oyo State offers all tiers of public health facilities from the primary to tertiary which are distributed across three health zones namely: Ibadan-Ibarapa, Oke-Ogun and Oyo-Ogbomosho health zones. ${ }^{12}$ The Ibadan-Ibarapa Health Zone where this study was carried out is made up of 13 local government areas namely: Ibadan North, Ibadan North West, Ibadan North East, Ibadan South East, Ibadan South West, Egbeda, Oluyole, Ona Ara, Lagelu, Ido, Ibarapa Central, Ibarapa East and Ibarapa North. This was a descriptive crosssectional facility based study involving heads of maternity section or the most senior health care worker involved in antenatal care and delivery services in each of the health care facilities visited in Ibadan-Ibarapa health zone. Using the health records at the Oyo State Ministry of Health, HMIS unit and LGAs records all primary and secondary health care facilities with an average of 30 deliveries in the last 6 months preceding the study were visited.

Data was collected with the use of an adapted structured proforma to obtain information from delivery records, a checklist to assess the availability of EmOC Services and a key informant interview with the head of maternity section using a three sectioned interviewer guide was conducted. The map of the Ibadan-Ibarapa health zone was digitized from Google Earth. As each health facility was being visited, the coordinates of the facilities were determined with the use of a calibrated GPS Essential Software for Android machine and these were further represented on the digitized map using Arc GIS software 10.1. The Key Informant Interview at the health facility level was done mainly by the researcher. All the Geographical Position Coordinates was also taken by the researcher after being trained by a Geographical Information System expert.

Facilities that could perform all the signal functions to qualify as a Basic EmOC except assisted delivery was regarded as "Basic EmOC minus one" while facilities that could perform all the functions of a Comprehensive EmOC except assisted or instrumental delivery was regarded as "Comprehensive EmOC minus one. This classification was applied in this study due to nonperformance of this signal function in all the primary and secondary health care facilities ${ }^{13,14}$. Data was entered using Epi Data to minimize errors and analyzed using Statistical Package for Scientific Solutions (SPSS) version 15.0. Descriptive statistics (frequencies, proportions and percentages) was used to display independent variables like human resources, infrastructure and equipment available at the health facilities, proportion of emergency obstetric care facilities across the Ibadan-Ibarapa health zone. The UN process indicators were calculated using the respective formulae and represented in appropriate tables. Median was used to summarize quantitative variables with skewed distribution such as number of beds in the facilities. Using Arc GIS Software 10.1, a spatial query was run to categorize the facilities into those not offering either BEmOC or CEmOC Services, those offering $\mathrm{BEmOC}$ and those offering $\mathrm{CEmOC}$ and geographical representation on a map was generated to determine geographical location of these facilities. 


\section{Results}

A total of 71 health care facilities (61 primary health care facilities and 10 secondary health care facilities) were visited in the 13 local governments in Ibadan-Ibarapa health zone and about $72 \%$ of these facilities were located in urban areas. Ibarapa East (11.3\%), Ibadan South West $(9.9 \%)$ and Lagelu (9.9\%) local government areas had the highest number of health facilities visited, whilst all other local government areas had an average of at least 4 health care facilities visited.

\section{Human resource}

All the secondary health care facilities met the recommended number and cadre of skilled health workers in their maternal units'. Each of the 10 secondary health care facilities had at least a medical doctor as against only $11.5 \%$ of the primary health centers. Also only $13.1 \%$ of the primary health care facilities had the recommended number of four midwives per facility compared to $80 \%$ of the secondary health care centers. Lower cadre health care workers mainly the CHEWs $(95.1 \%)$, Health Assistants (86.9\%) and CHOs (83.6\%) manned the primary health care facilities. About a fifth of the primary health care facilities had a laboratory scientist/technician (24.6\%) and a pharmacist/pharmacy technician (16.4\%) compared to $80 \%$ and $60 \%$ respectively in the secondary health care facilities. Obstetricians were present in 6 secondary health care facilities; anaesthetist/ anaesthetic nurse in 4 secondary health care facilities and 2 secondary health care facilities had 2 paediatricians. (Table 1)

\section{Infrastructure and basic services}

The Primary Health Care facilities had a median of six beds compared to the Secondary Health Care facilities had thirty four beds. Almost all the facilities are connected to the National Grid (93\%) but with less than half of them reporting the availability of standby generators. Only five (8.2\%) of the 61 primary health care facilities reported the absence of any source of electricity supply. The main source of water in the primary healthcare facilities was either the well $(41 \%)$ or borehole $(37.7 \%)$, but a lower proportion of these was seen in secondary health care facilities where the piped borne water $(40 \%)$ was more prevalent. Just about a third of the health care facilities had running water in either the delivery room, post-natal room or operating theatres, though this was higher in secondary health care facilities. Staff -owned cell phones were the major means of communication in all the health facilities. About seventy per cent of all the facilities did not have any means of transportation of patients for referral purposes with only a third of the primary health care facilities reported use of any functional means of transportation unlike secondary health facilities where 6 out of the 10 facilities had a functional means of transportation. The major means of transportation reported was a motor vehicle ambulance. Only $72.1 \%$ of the primary health care facilities had available 24 hours obstetric and neonatal services unlike all the secondary health care facilities. Only about a third of the health care facilities had hindrances to drug supply with a higher proportion in the primary health care facilities $(32.7 \%)$ than secondary health care facilities $(22.2 \%)$.

\section{Equipment}

The primary and secondary health care facilities had a fair complement of equipment for essential obstetric care. Apart from functional oxygen cylinder which was not present in any of the primary health care facilities but in 5 of the 10 secondary facilities, at least $75 \%$ of the primary facilities and nearly all the secondary health care facilities had fetal stethoscope, sphygmomanometer, thermometer, examination table, delivery table, forceps, scissors and sutures/syringe/latex . Only a third of the facilities had vacuum aspirator, and 13\% had vacuum extractor with a higher proportion of secondary health care facilities having this equipment. The partograph was available in only $18.3 \%$ of all the facilities visited and also present in a higher proportion of the secondary health care facilities. Parenteral oxytocics (59.2\%), antibiotics $(29.6 \%)$ and anticonvulsants $(14.1 \%)$ were also present in a fairly considerable proportion in all the facilities visited.

\section{Performance of emergency obstetric care services}

Manual removal of placenta $(66.7 \%)$ was the most common signal function performed in the primar 
Table 1: Distribution of Human Resources Present at the Primary and Secondary Health Care Facilities Visited in Ibadan-Ibarapa Health Zone.

\begin{tabular}{|c|c|c|c|}
\hline $\begin{array}{l}\text { Number and cadre of health care worker } \\
\text { present }\end{array}$ & $\begin{array}{l}\text { Primary } \\
n=61 \\
\text { No. }(\%)\end{array}$ & $\begin{array}{l}\begin{array}{l}\text { Secondary } \\
\mathrm{n}=10 \\
\text { No. }(\%)\end{array} \\
\end{array}$ & $\begin{array}{l}\text { Total } \\
\text { n=71 } \\
\text { No. }(\%) \\
\end{array}$ \\
\hline \multicolumn{4}{|l|}{ Doctor } \\
\hline None & $54(88.5)$ & $0(0.0)$ & $54(76.1)$ \\
\hline One & $7(11.5)$ & $3(30.0)$ & $10(12.7)$ \\
\hline Two or more & $0(0.0)$ & $7(70.0)$ & $7(11.2)$ \\
\hline \multicolumn{4}{|l|}{ Nurse/Midwife } \\
\hline None & $11(18.0)$ & $0(0.0)$ & $11(15.5)$ \\
\hline One & $23(37.7)$ & $0(0.0)$ & $23(32.4)$ \\
\hline Two or more & $27(31.1)$ & $10(100.0)$ & $37(52.1)$ \\
\hline \multicolumn{4}{|l|}{ СHO } \\
\hline None & $10(16.4)$ & $8(80.0)$ & $18(25.4)$ \\
\hline One & $22(36.1)$ & $1(10.0)$ & $23(32.4)$ \\
\hline Two or more & $29(47.5)$ & $1(10.0)$ & $30(42.2)$ \\
\hline \multicolumn{4}{|l|}{ CHEW } \\
\hline None & $3(4.9)$ & $7(70.0)$ & $10(14.1)$ \\
\hline One & $6(9.8)$ & $0(0.0)$ & $6(8.5)$ \\
\hline Two or more & $52(85.3)$ & $3(30.0)$ & $55(77.4)$ \\
\hline \multicolumn{4}{|l|}{ Health Assistant } \\
\hline None & $8(13.1)$ & $5(50.0)$ & $13(18.3)$ \\
\hline One & $9(14.8)$ & $0(0.0)$ & $9(12.7)$ \\
\hline Two or more & $44(72.1)$ & $5(50.0)$ & $49(69.0)$ \\
\hline \multicolumn{4}{|l|}{ Laboratory Scientist / Technician } \\
\hline None & $46(75.4)$ & $2(20.0)$ & $48(67.6)$ \\
\hline One & $11(18.0)$ & $3(30.0)$ & $14(19.7)$ \\
\hline Two or more & $4(6.6)$ & $5(50.0)$ & $9(12.7)$ \\
\hline \multicolumn{4}{|l|}{ Pharmacist/Pharmacy Technician } \\
\hline None & $51(83.6)$ & $4(40.0)$ & $55(77.5)$ \\
\hline One & $9(14.8)$ & $2(20.0)$ & $11(15.5)$ \\
\hline Two or more & $1(1.6)$ & $4(40.0)$ & $5(7.0)$ \\
\hline
\end{tabular}

health care centers closely followed by administration of parenteral oxytocics $(65.0 \%)$ and antibiotics (63.3\%). Almost all the secondary health facilities performed all the recommended comprehensive emergency obstetric care signal functions except blood transfusion $(70.0 \%)$ and caesarean section $(60.0 \%)$. Instrumental delivery was not performed at either the primary nor secondary health care facilities. (Figure 1) Only $8(13.1 \%)$ primary health care facilities met the UN criteria for Basic Emergency Obstetric Care Services minus 1 whilst $6(60.0 \%)$ secondary health care facilities met the criteria for Comprehensive Emergency Obstetric Care Services minus 1. Majority of the facilities meeting this criterion were located in the urban local governments for both primary (15.2\%) and secondary $(80.0 \%)$ health care facilities respectively. (Figure 2) Egbeda, Ido, Oluyole and Ibarapa North local governments did not have any facility meeting either the BEmOC or CEmOC minus 1 criteria. Ibadan North East, South East, Ona Ara and Lagelu local governments had at least one BEmOC minus 1 facility while Ibadan North, South West and Ibarapa East had at least one CEmOC minus 1 facility. Only one urban (Ibadan North West) and rural (Ibarapa Central) local government areas had at least one BEmOC minus 1 and CEmOC minus 1 facility respectively. (Table 2)

\section{Availability and Accessibility of EMOC services.}

Table 2 also shows the amount of EmOC Coverage per 500,000 population based on the WHO UN process indicators. This shows that the coverage of BEmOC in the 13 local governments ranged from 0 5.4 BEmOC facilities per 500,000 population while coverage for $\mathrm{CEmOC}$ ranged from 0-3.9 CEmoC facilities per 500,000 population. An overall coverage of the Ibadan- Ibarapa zone was 1.2 BEmOC per 500,000 population and 9.1 CEmOC per 500,000 population. The number of CEmOC for the Ibadan-Ibarapa was adequate for the population whilst that for BEmOC was grossly inadequate. Ibadan North West and Ibarapa Central were the only Local Government Areas that had adequate 
Figure 1: Proportion of the Facilities in Ibadan-Ibarapa Health Zone Performing the UN Recommended BEmOC and CEmOC Signal Functions in Both the Primary and Secondary Facilities in the last three Months Preceding the Study.

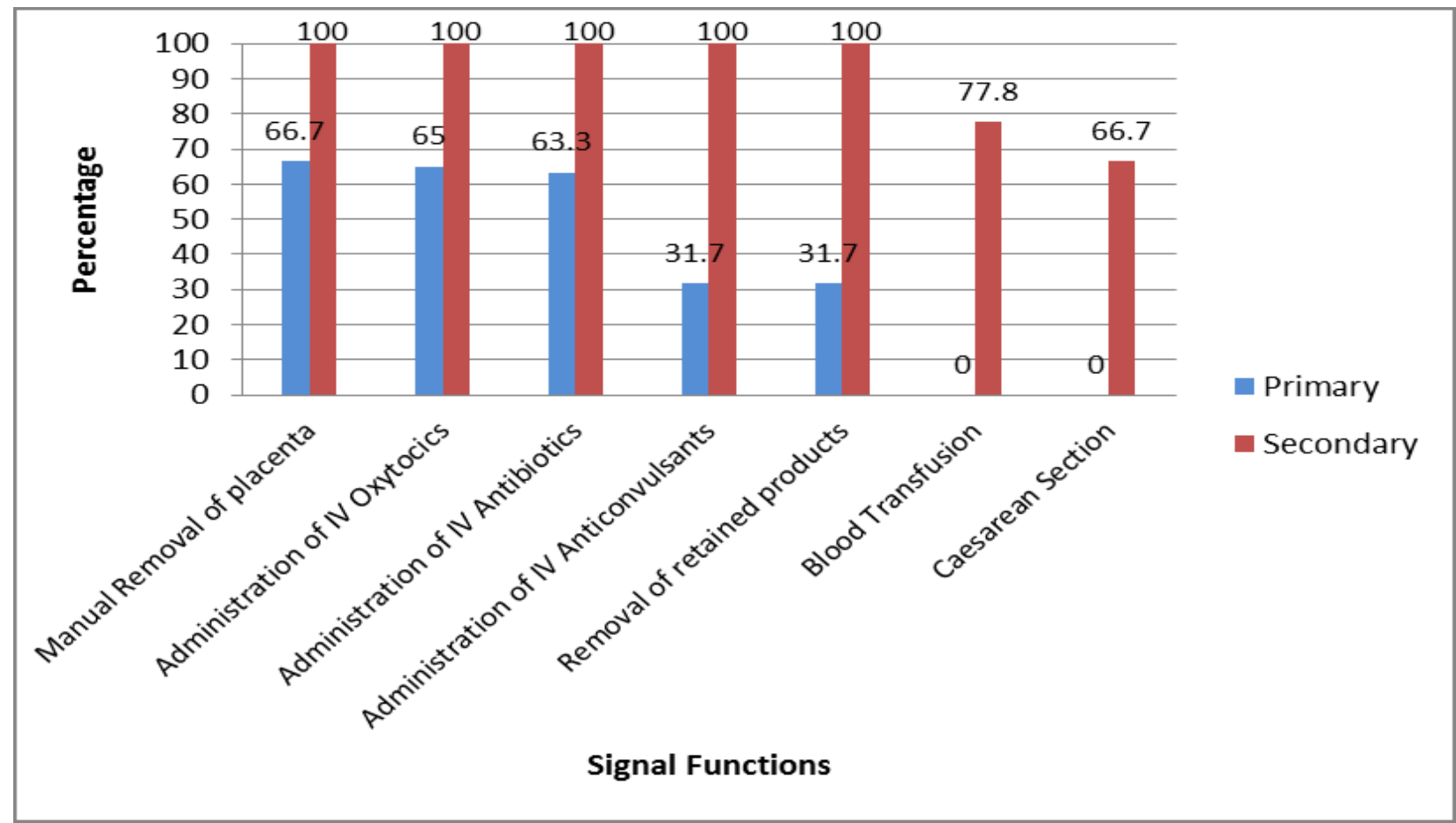

Figure 2: Proportion of Facilities meeting the Recommended UN signal Functions for BEmOC and CEmoC in the Primary and Secondary Health Care Facilities Visited in Ibadan Ibarapa Health Zone.

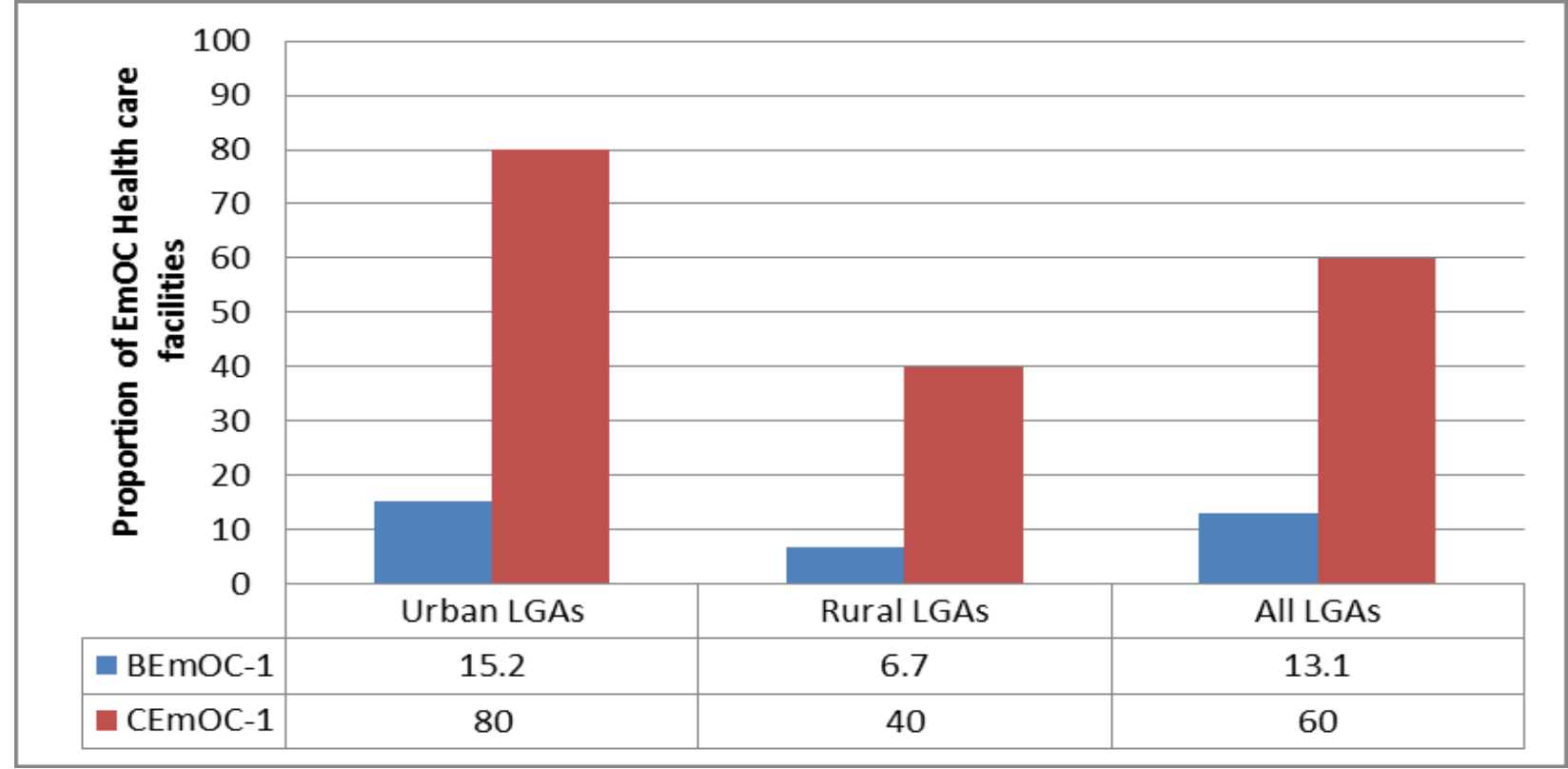

number of facilities for both BEmOC and CEmoC while Lagelu and Ona Ara Local Government Areas had enough BEmOC facilities only. Also Ibadan North, Ibadan South West and Ibarapa East Local Government Areas had adequate numbers of
CEmOC facilities. Figure 3 shows that both the $\mathrm{BEmOC}$ and $\mathrm{CEmOC}$ facilities are clustered around the Ibadan Metropolis i.e. (Ibadan North, Ibadan North East, Ibadan North West, Ibadan South East, and Ibadan South West) and even those in other 
Table 2: Amount of EmOC Coverage over 500,000 Population in Ibadan-Ibarapa Health Zone, Oyo State

\begin{tabular}{|c|c|c|c|c|c|c|c|}
\hline $\begin{array}{l}\text { Name of Local } \\
\text { Government }\end{array}$ & \multirow{2}{*}{$\begin{array}{l}\text { Estimated } \\
\text { population }\end{array}$} & \multirow{2}{*}{$\begin{array}{l}\text { Existing } \\
\text { facilities } \\
\text { services } \\
\text { Basic } \\
\text { EmOC }\end{array}$} & \multirow{2}{*}{$\begin{array}{l}\begin{array}{l}\text { Number of } \\
\text { providing }\end{array} \\
\text { Comprehensive } \\
\text { EmOC }\end{array}$} & \multicolumn{2}{|c|}{ Basic EmOC } & \multicolumn{2}{|c|}{ Comprehensive EmOC } \\
\hline & & & & $\begin{array}{l}\text { BEmOC } \\
\text { Coverage }\end{array}$ & $\begin{array}{l}\text { Recommended } \\
\text { coverage of } \\
\text { BEmOC }\end{array}$ & $\begin{array}{l}\text { CEmoC } \\
\text { Coverage }\end{array}$ & $\begin{array}{l}\text { Recommended } \\
\text { coverage of } \\
\text { CEmoC }\end{array}$ \\
\hline Egbeda & 351034 & 0 & 0 & 0.0 & 2.8 & 0.0 & 0.7 \\
\hline Ibadan North & 382478 & 0 & 1 & 0.0 & 3.1 & 1.4 & 0.8 \\
\hline Ibadan North & & & & & & & \\
\hline East & 411905 & 1 & 0 & 1.2 & 3.3 & 0.0 & 0.8 \\
\hline Ibadan & & & & & & & \\
\hline West & 190536 & 1 & 1 & 2.6 & 1.5 & 1.2 & 0.4 \\
\hline Ibadan & & & & & & & \\
\hline East & 331676 & 1 & 0 & 1.5 & 2.7 & 0.0 & 0.7 \\
\hline Ibadan & & & & & & & \\
\hline West & 352295 & 0 & 2 & 0.0 & 2.8 & 3.0 & 0.7 \\
\hline Ibarapa Central & 128383 & 1 & 1 & 3.9 & 1.0 & 1.4 & 0.3 \\
\hline Ibarapa East & 147391 & 0 & 1 & 0.0 & 1.2 & 3.9 & 0.3 \\
\hline Ibarapa North & 126030 & 0 & 0 & 0.0 & 1.0 & 0.0 & 0.3 \\
\hline Ido & 128734 & 0 & 0 & 0.0 & 1.0 & 0.0 & 0.3 \\
\hline Lagelu & 184456 & 2 & 0 & 5.4 & 1.5 & 0.0 & 0.4 \\
\hline Oluyole & 252735 & 0 & 0 & 0.0 & 2.0 & 0.0 & 0.5 \\
\hline Ona Ara & 330446 & 2 & 0 & 3.0 & 2.6 & 0.0 & 0.7 \\
\hline Total & 3318099 & 8 & 6 & 1.2 & 26.5 & 9.1 & 6.6 \\
\hline
\end{tabular}

Figure 3: Geographical Distribution of BEmOC Minus 1 and CEmoC Minus 1 Facilities in Ibadan Ibarapa Health Zone

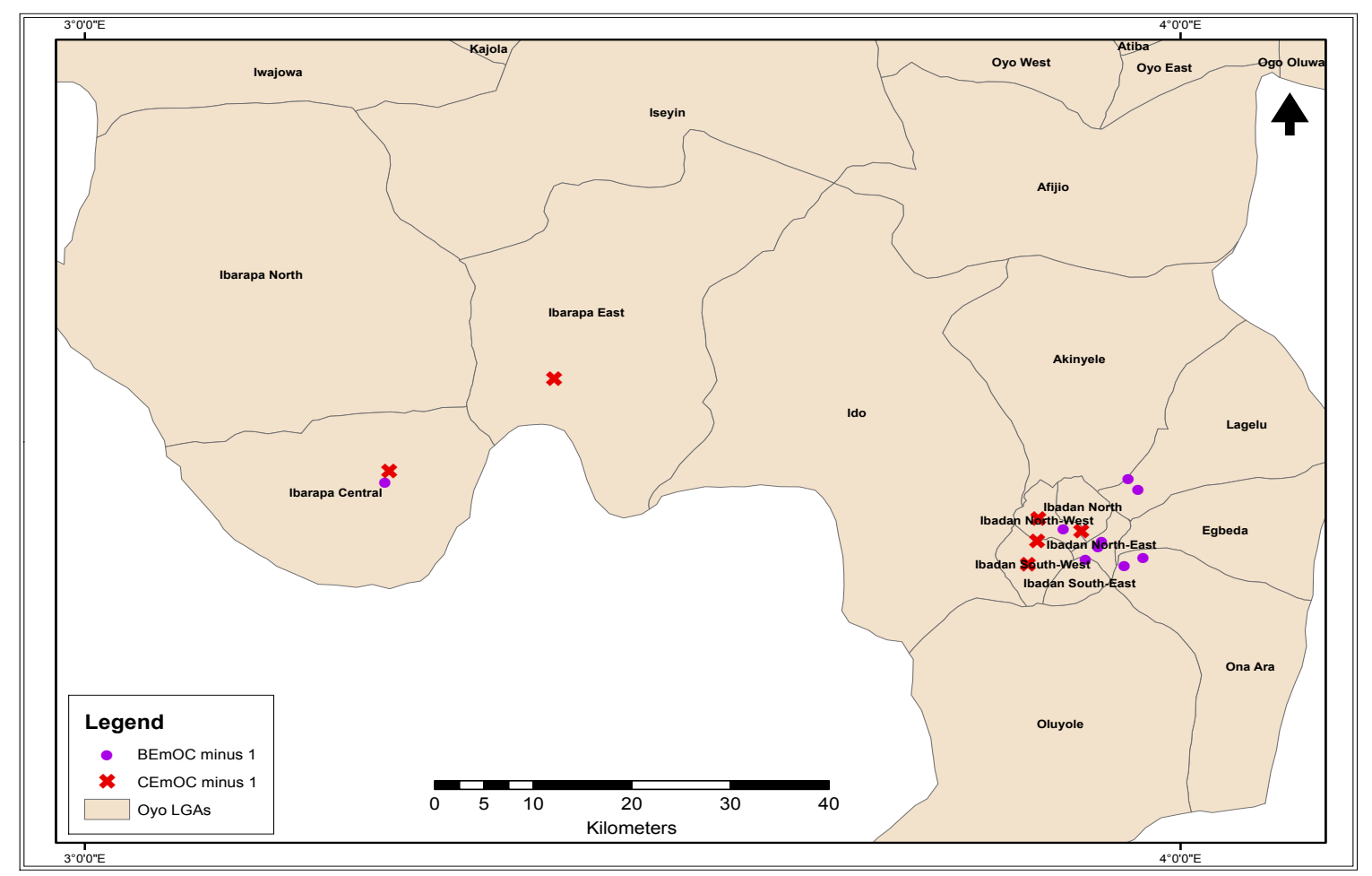

local governments like Ona Ara and Lagelu are close to the boundary of the main Ibadan metropolis. In Egbeda local government, the health facilities meeting the inclusion criteria are located close to the urban areas. Although in Ibadan North and Ibadan
South West Local Government Areas, the facilities were still fairly distributed across the area but they did not all meet the BEmOC criteria. Also in Ibadan North East, Ido and Oluyole local government areas, the facilities were clustered on one side of the local 
government area. In the rural local government areas (Ibarapa North, Ibarapa Central and Ibarapa East) the health care facilities are also clustered in the main town and located along major roads. Only $3.1 \%$ of deliveries in the Ibadan-Ibarapa Health zone took place in an Emergency Obstetric Care Facility using the Crude Birth Rate in Nigeria of 40.2 per 1000 and estimated number of deliveries in the facilities offering both Basic and Comprehensive Emergency Obstetric Care Services.

\section{Discussion}

The results illustrated a continued lack of simple care package of life saving interventions (EmOC) as fully functional $\mathrm{BEmOC}$ facilities were almost nonexistent in the sixty one primary health care facilities visited although $\mathrm{CEMOC}$ facilities were adequate in number. The overall coverage for BEmOC was $1.2 \mathrm{BEmOC}$ facilities per 500,000 population and for $\mathrm{CEmOC}$ was 9.1CEmOC facilities per 500,000. The UN recommended proportion of CEmOC for the population of IbadanIbarapa Health Zone $(3,318,099)$ was 7 CEmOC facilities as against 9 CEmOC facilities observed in this study; this was a welcome development. But the finding of only $1 \mathrm{BEmOC}$ facility in this health zone as against $27 \mathrm{BEmOC}$ facilities recommended for the population of the health zone is of great concern to the effective delivery of emergency obstetric care services. This shows a gross lack of basic emergency obstetric care services available for over a half of the population in Oyo State which has a total population of $5,580,894$.

This pattern of availability of EmOC reported in this study seems to be a universal finding in many EmOC surveys done in most developing countries. In a baseline assessment of EmOC facilities in four African countries (Uganga, Kenya, Southern Sudan and Rwanda) by Pearson et al, it was found that the number of $\mathrm{CEmOC}$ facilities were more than the recommended minimum while the number of BEmOC facilities in all the four countries were below the recommended minimum ${ }^{15}$. Paxton et al also examined the global patterns of the availability of EmOC functions and concluded that CEmOC facilities are usually available to meet the recommended minimum, but $\mathrm{BEmOC}$ facilities are consistently not available in sufficient numbers ${ }^{6}$.

The findings in this study also corroborates a previous study covering 12 States across the 6 geopolitical zones of Nigeria where only one state met the recommended number of BEmOC per 500,000 population but all the 12 states had adequate number of $\mathrm{CEmOC}^{11}$.

In this study, facilities were classified as BEmOC minus 1 and $\mathrm{CEmOC}$ minus 1 and the major missing signal function for these facilities not meeting the UN process indicator standard was nonperformance of assisted vaginal delivery, which at the primary health care level essentially means vacuum delivery. The main underlying reason is that of lack of equipment and skills and the practice of assisted vaginal delivery had not been a part of the curriculum in most nursing and midwifery schools in Nigeria ${ }^{11}$. This finding is in line with most studies as the performance of this signal function is usually the least. A study done in Nairobi, Kenya using the 6 signal functions for $\mathrm{BEmOC}$, reported that no facility met the criteria for BEmOC but when assisted vaginal delivery was removed, 10 facilities met the criteria ${ }^{16}$. Also a study done across six countries in Africa, Nigeria inclusive, identified performance of assisted vaginal delivery and removal of retained products of conception as the least performed functions ${ }^{17}$. This might also be due to the complex nature of these procedures as they require special training for the acquisition of these skills.

The signal functions requiring little skills like administration of parental antibiotics and oxytocics were the most performed signal function across all facilities as observed in this study. This is in agreement with most studies across the geopolitical zones of Nigeria as a study done in 121 Nigerian health care facilities reported administration of parental antibiotics as the most frequently performed $^{18}$. On the other hand this study identified administration of parenteral anticonvulsants and removal of retained products of conception as the least performed signal functions in the primary health care facilities which was also in line with the study done in the six countries, Nigeria inclusive ${ }^{17}$. Pre-eclampsia and eclampsia are the second most common cause of maternal deaths globally and proper use of anticonvulsants has the potential of averting up to $85 \%$ of these deaths. Although this study showed provision of this service was poor in the primary health care facilities, it is however performed at all the secondary health care facilities. The reason for non-performance at the primary health care facilities might be due to prompt referral as most primary health care centers do not wait for this complication to occur before referral. This 
might also be due to lack of appropriate drug $\left(\mathrm{MgSO}_{4}\right)$ or lack of skills for its use. A majority of the health care facilities were clustered in the main Ibadan metropolitan local governments and even the facilities meeting the EmOC criterion were close to the boundaries of the main local governments in Ibadan. The secondary health facilities were located fairly across the entire region but the primary health care facilities were sparsely distributed. This study also identified some facilities as BEmOC minus 2 which if upgraded can improve the geographical distribution of Emergency Obstetric Care Services. These facilities were also clustered around the urban and peri urban areas, adjacent to the roads while a large proportion of people in the rural and remote areas remain virtually without services. This finding corroborates those of a study done in Nepal to assess the geographical distribution of facilities ${ }^{19}$ and another study carried out in Zambia which reported that geographical access to EmOC services in rural areas was very low with less than $25 \%$ of the population living within $15 \mathrm{~km}$ of any EmOC facility $^{20}$.

The study findings were also in line with a study carried out in a West African country (Ghana) which reported that geographical access to EmOC facilities was very poor in the rural areas, with nearly a third of the women of child bearing age in Ghana living more than four hours from top-tier facilities likely to offer partial EmOC (BEmOC-1 or BEmOC-2) or CEmOC facility and are thus at substantially greater risk of dying in the event of unforeseen circumstances during child birth ${ }^{21}$. In conclusion, this study found out that the availability of Basic EmOC Services in the Ibadan-Ibarapa health zone was grossly inadequate, although secondary health care facilities were more than enough for the population. In addition, utilization of these EmOC services by women was found to be below the recommended UN guidelines. The facilities are geographically distributed within the Ibadan Metropolis and thus leaving rural settlements of these local governments with not enough facilities to meet the minimum requirements of emergency obstetric care needed.

\section{References}

1. WHO (2012). "Fact Sheet." WHO Publications. www.who.int/mediacenter/factsheets/fs348/en/index.h tm. accessed, June 2012.

2. WHO (2012). "World Bank Annual Report 2012." http://go.worldbank.org/ZJCK7BD440. Accessed
June 2012.

3. CDC (2011). "Maternal and Reproductive Health Issues." www.cdc.org/reproductivehealth/index.htm. Accessed May 2012

4. Ronsmans, C. and W. J. Graham (2006). "Maternal mortality: who, when, where, and why." Lancet 368(9542): 1189-1200.

5. Bailey, P., et al. (2006). "Measuring progress towards the MDG for maternal health: including a measure of the health system's capacity to treat obstetric complications." International journal of gynaecology and obstetrics: the official organ of the International Federation of Gynaecology and Obstetrics 93(3): 292299.

6. Paxton, A., et al. (2005). "The evidence for emergency obstetric care." International journal of gynaecology and obstetrics: the official organ of the International Federation of Gynaecology and Obstetrics 88(2): 181193.

7. Essendi, H., et al. (2011). "Barriers to formal emergency obstetric care services' utilization." J Urban Health 88 Suppl 2: S356-369.

8. National Population Commission, ICF Macro (2009). "Nigerian Demographic and Health Survey, 2008."

9. WHO (2009). "Monitoring emergency obstetric care services: A Handbook." ISBN 9789241547734

10. Ameh, C., et al. (2012). "Status of emergency obstetric care in six developing countries five years before the MDG targets for maternal and newborn health." PLoS One 7(12): e49938.

11. Fatusi AO Ijadunola KT (2003). "National study of essential obstetric care." UNFPA FMOH..

12. Oyo State Government (2011). "Oyo State Ministry of Health Report."

13. Paxton, A., et al. (2003). "Using the UN process indicators

14. of emergency obstetric services: Question and Answers." AMDD Workbook.

15. AMDD Working Group on Indicators (2003). "Program note: using UN process indicators to assess needs in emergency obstetric services: Morocco, Nicaragua and Sri Lanka." International Journal of Gynecology and Obstetrics 80(2): 222-230.

16. Pearson, L. and R. Shoo (2005). "Availability and use of emergency obstetric services: Kenya, Rwanda, Southern Sudan, and Uganda." International journal of gynaecology and obstetrics: the official organ of the International Federation of Gynaecology and Obstetrics 88(2): 208-215

17. Ziraba, A. K., et al. (2009). "The state of emergency obstetric care services in Nairobi informal settlements and environs: Results from a maternity health facility survey." BMC Health Services Research 9(1): 1-8.

18. Ijadunola, K. T., et al. (2007). "Unavailability of Essential Obstetric Care Services in a Local Government Area of South-West Nigeria." Journal of Health, Population, and Nutrition 25(1): 94-100.

19. Erim, D. O., et al. (2012). "A Rapid Assessment of the Availability and Use of Obstetric Care in Nigerian Healthcare Facilities." PLoS One 7(6): e39555.

20. Department of Community Medicine and Family Health Institute of Medicine Kathmandu Nepal (2004). "Study on Utilization of Emergency Obstetric Care(EMoC) in selected district of Nepal." 
21. Gabrysch, S., et al. (2011). "Availability and distribution of, and geographic access to emergency obstetric care in Zambia." International journal of gynaecology and obstetrics: the official organ of the International
Federation of Gynaecology and Obstetrics 114(2): 174-179.

22. Gething, P. W., et al. (2012). "Geographical access to care at birth in Ghana: a barrier to safe motherhood." BMC Public Health 12: 991. 